\title{
Inflammatory Bowel Diseases: It's Time for the Adenosine System
}

\author{
Luca Antonioli ${ }^{1 *}$, Matteo Fornai ${ }^{1}$, Carolina Pellegrini ${ }^{2}$, Lorenzo Bertani ${ }^{3}$, \\ Zoltan H. Nemeth ${ }^{4,5}$ and Corrado Blandizzi ${ }^{1}$ \\ ${ }^{1}$ Department of Clinical and Experimental Medicine, University of Pisa, Pisa, Italy, ${ }^{2}$ Department of Pharmacy, University of \\ Pisa, Pisa, Italy, ${ }^{3}$ Department of Translational Research and New Technologies in Medicine and Surgery, University of Pisa, \\ Pisa, Italy, ${ }^{4}$ Department of Surgery, Morristown Medical Center, Morristown, NJ, United States, ${ }^{5}$ Department of \\ Anesthesiology, Columbia University Medical Center, New York, NY, United States
}

Keywords: adenosine, adenosine receptor, immune system, intestinal motility disorder, inflammatory bowel diseases, novel drugs and targets

\section{INTRODUCTION}

\section{The Adenosine System: Enzymes, Transporters, and Receptors}

Over the years, a number of evidences have pointed out the relevant contribution of the adenosine system in the regulation of different physiological functions, highlighting a deep involvement of this nucleoside in shaping the digestive functions (1). Of note, such modulatory effects are tightly related to the levels reached by this nucleoside in the biophase of its own receptors (2). In this regard, it has been well reported that the adenosine levels vary considerably based on the health status of the tissues (3).

Under physiological conditions, low levels of adenosine are detected in the extracellular milieu, which stems mainly from the intracellular activity of S-adenosylhomocysteine hydrolase, which converts the S-adenosylhomocysteine into adenosine (1). Once synthesized, adenosine is extruded from the cells via nucleoside transporters, classified into: (a) equilibrative nucleoside transporters (ENTs), bidirectional transporters, acting on the intra- and extracellular levels reached by the nucleoside; (b) the concentrative nucleoside transporters (CNTs), promoting the intracellular influx of adenosine against its concentration gradient. Once re-uptaken intracellularly, adenosine is quickly phosphorylated into adenosine monophosphate (AMP) by adenosine kinase or deaminated into inosine via the catabolic enzyme adenosine deaminase (1). Under pathological conditions, the extracellular levels of adenosine increased markedly, mainly via the up-regulation of the ecto-nucleoside triphosphate diphosphohydrolase 1 (CD39)-5' -nucleotidase (CD73) enzyme axis, which quickly convert the extracellular adenosine 5'-triphosphate (ATP) into adenosine (4).

The extracellular levels of adenosine are tightly controlled by adenosine deaminase which converts this nucleoside into inosine, and then to the end product uric acid via xanthine oxidase (5). In parallel, adenosine kinase also takes part to finely tune the extracellular adenosine concentration, phosphorylating it once recovered inside the cell (1).

The physiological and pathophysiological activity of adenosine are mediated by the engagement of four specific G-protein-coupled receptors named $A_{1}, A_{2 A}, A_{2 B}$, and $A_{3}$ (6). The $A_{1}$ and $A_{3}$ receptors, once stimulated, induce an intracellular release of calcium via interaction with $G_{i}, G_{q}$, and $G_{o}$ proteins (7). The $A_{2 A}$ and $A_{2 B}$ receptors, related with $G_{s}$ or $G_{o l f}$, activate adenylyl cyclase (7). Of note, $A_{2 B}$ receptors can also elicit the activation of the phospholipase $C$ via $G_{q}$ protein (7).

Citation:

Antonioli L, Fornai M, Pellegrini C Bertani L, Nemeth ZH and Blandizzi C (2020) Inflammatory Bowel Diseases:

It's Time for the Adenosine System. Front. Immunol. 11:1310.

doi: 10.3389/fimmu.2020.01310

\section{Adenosine System in IBD Pathophysiology}

IBDs are chronic relapsing disorders affecting the digestive tract, clinically classified as Crohn's disease or ulcerative colitis based on symptoms, disease location, and histopathological features (8).

A common denominator observed in IBD patients is deregulated intestinal mucosa functions as well as an exuberant activity of immune cell populations $(9,10)$. Indeed, in IBD patients 
the barrier function appears critically compromised, thus leading to an increased permeability to noxious intraluminal stimuli. In particular, the bacteria, overwhelming the intestinal barrier, infiltrate the lamina propria triggering the mucosal immune system activity and spurring the inflammatory process (11). In parallel, the IBD patients display both a T cell dysfunction as well as an antigen-presenting cell alteration $(9,10)$.

Clinically, it has been reported that Crohn's disease can affect any part of the digestive tract (12). In particular, this disorder is characterized by "patches," affecting some areas of the gut, leaving other sections completely unaltered (12). Histologically, Crohn's disease displays a transmural inflammation of the bowel wall (12). By contrast, ulcerative colitis is limited to the colon and the rectum, with an inflammation occurring only in the innermost layer of the lining of the intestine (12).

Immunologically, Crohn's disease is characterized by a $\mathrm{T}_{\mathrm{H} 1} / \mathrm{T}_{\mathrm{H} 17}$ paradigm, leading to a marked release of IL-1 $\beta$, IL-6, IL-12, IL-17, IL-21, IL-22, IL-23, IL-26, TNF, and IFN- $\gamma$ (13). The ulcerative colitis patients showed a $\mathrm{T}_{\mathrm{H} 2} / \mathrm{T}_{\mathrm{H} 9}$ paradigm, which determines a massive production of IL-4, IL-5, IL-9, IL-13, and IL-25 (13).

Over the years, the increasing availability of different preclinical models of IBDs, allowed a better understanding of the pathophysiological mechanisms underlying these diseases (14). At present, more than 60 animal models have been established to study IBD, distinguished in chemically induced, congenial mutant, cell-transfer, and genetic models (14). Among the chemical-induced colitis models, the dinitro- or trinitrobenzene sulfonic acid (DNBS or TNBS, respectively), oxazolone and dextran sulfate sodium (DSS)-induced colitis are widely employed (15). DNBS- or TNBS-administration elicited a $\mathrm{T}_{\mathrm{H} 1 /} \mathrm{TH}_{17}$ immune response, closely mimicking the Crohn's disease features (15). The DSS-induced colitis, despite being widely employed, is a spurious model, displaying a $\mathrm{T}_{\mathrm{H} 1} / \mathrm{T}_{\mathrm{H} 2}$ cytokine pattern (15). By contrast, ulcerative colitis in humans is well mimicked by the oxazolone-induced colitis, which typically exhibits a $\mathrm{T}_{\mathrm{H} 2}$ immune response (15).

Among the genetically engineered murine models of colitis, the IL-10-knockout mice spontaneously develop a transmural pancolitis and cecal inflammation, similar to human Crohn's disease (14). In addition, the adoptive transfer models, induced by the selective transfer of immune cell types, usually $\mathrm{CD} 4^{+} \mathrm{T}$ cells, in immunodeficient animals, provided relevant information about the role of $\mathrm{T}$ cells in shaping the mucosal immunity (14).

In parallel, the availability of a number of cell culture systems allowed to in vitro dissect the relevance of various cell populations in IBD onset and development (16). However, the cell culture models display several points of criticisms. Indeed, most of the cell lines employed are often immortalized neoplastic cell lines (16). In particular, the colonic cell lines Caco-2, HT29 and T84, despite displaying morphological and functional features of differentiated intestinal epithelial cells, they are characterized by neoplastic features in terms of phenotype and metabolism, thus not adequately representing the physiological or the inflammatory condition (16). In this regard, the primary human intestinal epithelial cells obtained from healthy subjects or IBD patients should be the most representative model, but unfortunately their employment is complicated by the extreme phenotype variability and by the reduced viability once in culture (16).

Over the years, several evidences highlighted a critical role of adenosine in the maintenance of intestinal homeostasis, and in orchestrating the interplay between the intestinal epithelial cells, the neuromuscular compartment and the enteric immune system (1). In particular, adenosine and its receptors demonstrated a profound reorganization in the inflammatory contexts, taking a significant part in shaping the immune responses (17). On these premises, several studies investigated the therapeutic potential of ligands acting on the adenosine system in the management of intestinal inflammation (17). However, a critical evaluation of the available pre-clinical studies about the efficacy of drugs acting on the adenosine system in managing the chronic inflammatory bowel diseases, is complicated by the heterogeneity of the in vivo and in vitro models employed, which could lead, in some cases, to conflicting results.

\section{Role of Adenosine System in Intestinal Inflammation}

Crohn's patients with active disease displayed an increased $\mathrm{A}_{2 \mathrm{~A}}$ receptor mRNA expression in colonic mucosa, while no changes were observed in patients with ulcerative colitis (18). Conversely, others reported a decreased mRNA and protein expression of $\mathrm{A}_{2 \mathrm{~A}}$ receptor in sigmoid colonic mucosa from active ulcerative colitis patients $(19,20)$. In addition, the authors observed that $\mathrm{A}_{2 \mathrm{~A}}$ receptor expression was oppositely related with miR-16 expression (19). In particular, miR-16, targeting the 3 '-UTR of $A_{2 A}$ receptor mRNA, has been found to inhibit $A_{2 A}$ receptor transcription (19). Zhang et al. (20) observed a correlation between the increase in miR-15 and a decreased expression of $\mathrm{A}_{2 \mathrm{~A}}$ receptor mRNA in colonic tissues from ulcerative colitis patients. The authors demonstrated in HT-29 cell lines that miR-15 downregulated $A_{2 A}$ receptor mRNA expression, which, in turn, decreased the activation of pro-inflammatory NF-кB signaling (20).

Several studies showed that in the presence of bowel inflammation, $\mathrm{A}_{2 \mathrm{~A}}$ receptors critically regulate $\mathrm{T}$ cell functions. Naganuma et al. (21) reported that co-transfer of CD45RB low or $\mathrm{CD} 25^{+}$Th cells lacking $\mathrm{A}_{2 \mathrm{~A}}$ receptors to immunodeficient mice transferred of pathogenic CD45RB high Th cells failed to prevent disease. Conversely, co-transfer of wild-type CD45RB ${ }^{\text {low }}$ or $\mathrm{CD}_{2} 5^{+}$Th cells prevented the onset of the disease, revealing a critical involvement of $\mathrm{A}_{2 \mathrm{~A}}$ receptor in the onset of experimental colitis.

The pharmacological activation of $\mathrm{A}_{2 \mathrm{~A}}$ receptors, via inosine administration, has exerted beneficial effects in animals with colitis induced by TNBS, indicating the $\mathrm{A}_{2 \mathrm{~A}}$ receptor activation as an intriguing pharmacological strategy for management of gut inflammation (22). Likewise, oral administration of PSB0777, a scarcely absorbed $A_{2 A}$ receptor agonist, alleviated bowel inflammation in oxazolone-induced colitis rats (23). However, treatment with CGS21680, a recognized selective $A_{2 A}$ receptor agonist failed in ameliorating a murine model of DSS-induced colitis (24). 
The discrepancy in term of efficacy about the pharmacological $\mathrm{A}_{2 \mathrm{~A}}$ receptor stimulation in the murine models of colitis, could be ascribable to the difference in the pathophysiological mechanisms underlying such experimental models. Indeed, it has been widely recognized that the $\mathrm{T}$ cells play a relevant role in the onset and development of TNBS or oxazolone colitis $(25,26)$, but not in DSS colitis (27). Of note, the main immunomodulatory action of $\mathrm{A}_{2 \mathrm{~A}}$ receptors is mainly targeted to $\mathrm{T}$ cell population and only marginally on other immune cell populations (28). In line with this evidence, a number of data showed a lack of efficacy of CGS 21680 in stemming the phlogistic process, such as the DSS colitis, mainly driven by macrophages $(29,30)$.

Besides $\mathrm{A}_{2 \mathrm{~A}}$ receptors, enteric immune and non-immune cells, with particular regard for intestinal epithelial cells, express $A_{2 B}$ receptors $(31,32)$. Indeed, both patients and mice with colitis displayed an increased $\mathrm{A}_{2 \mathrm{~B}}$ receptor expression in the intestinal epithelial cells (33). In this context, $A_{2 B}$ receptors hold a key role in the maintenance of gut epithelial barrier integrity and functions, through the regulation of secretory activity, permeability and interaction with bacteria, pivotal factors implicated in IBD (33). Of note, the endothelial cells and the macrophages also showed the presence of $\mathrm{A}_{2 \mathrm{~B}}$ receptors (34). Previous studies showed that the pharmacological block or gene deletion of $\mathrm{A}_{2 \mathrm{~B}}$ receptor ameliorated the colitis in mice $(35,36)$. Conversely, Frick et al. reported that both the genetic or pharmacological ablation of $\mathrm{A}_{2 \mathrm{~B}}$ receptors augmented the course of colitis, thus suggesting a protective role for $A_{2 B}$ receptors (37). In addition, they demonstrated that mice with $A_{2 B}$ receptor gene deletion in intestinal epithelial cell were less susceptible to the development of bowel inflammation, thus confirming a pivotal role of $\mathrm{A}_{2 \mathrm{~B}}$ in the protection against colitis, suppression of inflammation as well as in preserving intestinal barrier integrity (38). These conflicting data regarding the role of $\mathrm{A}_{2 \mathrm{~B}}$ receptors in bowel inflammation could result from different experimental designs, environmental variability and differences in knockout murine strains, including variation in bacterial flora composition.

Of interest, a role of $\mathrm{A}_{3}$ adenosine receptors in the pathophysiological mechanisms of IBDs has also been described. Indeed, both patients with ulcerative colitis and in animals with experimental colitis displayed a decrease in $A_{3}$ receptor expression in colonic tissues $(18,39,40)$. However, others reported an increased level of $\mathrm{A}_{3}$ receptors in peripheral blood mononuclear cells of Crohn's patients (41). In a recent study, Ren et al. (42) showed that patients with ulcerative colitis were characterized by a decreased $A_{3}$ receptor expression along with an increase in TNF and IL-1 $\beta$ concentrations as well as NF- $\kappa \mathrm{B}$ p65 expression in colonic mucosa. The pharmacological stimulation of $\mathrm{A}_{3}$ receptors via 2-Cl-IB-MECA reduced the TNF and IL-1 $\beta$ levels and counteracted the NF- $\kappa$ B p65 activation in colonic tissues from UC patients, thus suggesting a role of $\mathrm{A}_{3}$ in the pathogenesis of bowel inflammation (42). Mabley et al. (43) demonstrated that IBMECA treatment to DSS mice, TNBS rats as well as IL$10^{-/-}$animals exerted beneficial effects on bowel inflammation, ameliorating the clinical symptoms and histological signs of inflammation and suppressed inflammation $(43,44)$. Conversely, gene deletion of $\mathrm{A}_{3}$ receptor in mice was associated with a lower susceptibility to the development of colitis induced by DSS (40).

Such conflicting findings could be ascribed to different experimental conditions, including differences in gut microbiota composition, regarded as an important factor in the development of colitis (45). In addition, it is worth noting that the ablation of $\mathrm{A}_{3}$ adenosine receptors determines an upregulation of other adenosine receptors, such as $\mathrm{A}_{2 \mathrm{~A}}$, which, in turn, exert protective effects in bowel inflammation (21).

Of interest, besides the adenosine receptors, the CD39/CD73 axis, involved in the adenosine synthesis, is emerging as a novel pharmacological target in IBD (4).

Gibson et al. observed a decreased expression of CD39 on $\mathrm{T}_{\text {regs }}$ from IBD patients when compared with healthy subjects (46). In addition, the authors reported that treatment with the antiTNF infliximab determined an increase in CD39 expression on $\mathrm{T}_{\text {regs }}$ (46). Bai et al. observed a decreased expression of CD39 in a Th17 subpopulation with suppressor activity of patients with IBDs (47). Others reported an increase in $\mathrm{CD} 39^{+} \mathrm{CD} 8^{+} \mathrm{T}$ cells in peripheral blood as well as in the lamina propria of Crohn's disease patients (48). Both $\mathrm{CD} 9^{+} \mathrm{Th} 17$ and $\mathrm{CD} 39^{+} \mathrm{CD} 8^{+}$ $\mathrm{T}$ cells have been found to exert immunosuppressive effects through the production of adenosine (48). Confirming the immunosuppressive role of CD39 in IBDs it has been observed that a single nucleotide polymorphism determining low levels of CD39 expression was related with a higher susceptibility to the development of Crohn's disease in a case-control cohort including 1,748 IBD patients and 2,936 controls (49). Taken together, these findings suggest a protective role of CD39 in patients with IBDs.

To better understand the role of CD39 in the pathogenesis of bowel inflammation has been well characterized by means of animal models of colitis. Friedman et al. showed that $\mathrm{CD}^{2} 9^{-/-}$mice displayed an enhanced inclination to DSSinduced colitis. Such an effect was rescued by the administration of exogenous ATPase apyrase (49). Conversely, others observed that TNBS mice with CD39 gene deletion were characterized by a lower severity of colitis as compared with wild type TNBS animals (50). In addition, they observed that the severity of oxazolone-induced colitis was comparable in CD39 KO mice as well as in wild-type animals (50). The explanation for these heterogenous results could be ascribed to the different experimental models of colitis employed. Indeed, the TNBS model shows clinicopathological features reminiscent to Crohn's disease while oxazolone-induced colitis resembles ulcerative colitis (26). However, further investigations in mice with cellspecific and temporal targeting of CD39 are needed to clarify the involvement of CD39 in bowel inflammation.

A critical role for CD73 in maintaining intestinal homeostasis has also been described (51-54). Doherty et al. displayed that patients with IBD were characterized by an increased numbers of circulating and colonic $\mathrm{CD} 73^{+} \mathrm{CD} 4^{+} \mathrm{T}$ cells during the active phase of inflammation and such an increase was counteracted following anti-TNF treatment (55). In addition, patients with active IBD displayed an increase in CD73 on $\mathrm{Th}_{17}$ cells (55).

In order to better clarify the role of CD73 in the onset of bowel inflammation, several studies have been carried out in 
pre-clinical models of colitis. One of these works demonstrated an increased expression of CD73 in colonic mucosa of mice treated with TNBS (51). In addition, the induction of colitis in $\mathrm{CD}^{-/-}$mice was associated with worsening clinical course and inflammation. On the same line, the pharmacological blockade of $\mathrm{CD} 73$ with the selective inhibitor $\alpha, \beta$-methylene ADP increased the severity of colitis in wild type TNBS mice (51). In addition, Bynoe et al. demonstrated that the protective effects of CD73 in bowel inflammation resulted from the induction of IFN- $\alpha \mathrm{A}$, whose administration reversed the deleterious CD73 phenotype (56). However, the activation of CD73 on $\mathrm{T}_{\text {regs }}$ was not dispensable for its protective effects in bowel inflammation. Moreover, the co-transfer of wild-type $\mathrm{T}_{\text {regs }}$ to $\mathrm{Rag}^{-/-}$mice exerted beneficial effects on bowel inflammation comparable to co-transfer of CD73 deficient $\mathrm{T}_{\text {regs }}$ (56). Based on these data, it is evident that the relevance of CD73 in the pathophysiology of the intestinal inflammation. In particular, by means of CD73 knockout mice, it has been demonstrated that a reduced expression of this enzyme in effector immune cells contribute to the IBD pathogenesis. Moreover, the critical role of CD73 in the maintenance of the colonic epithelium integrity has been also observed, as corroborated by the marked degree of colonic inflammation and tissue damage in CD73 knockout mice.

Growing evidence highlights an involvement of ADA in the IBD pathophysiology (5). Maor et al. showed that Crohn's patients during the active phase of the disease displayed higher circulating ADA and ADA2 levels in comparison with patients in remission as well as in healthy subjects (57). In addition, the increased circulating ADA levels in patients with ulcerative colitis were found to correlate with the severity of the disease (58). An enhanced expression of ADA was also observed in animal models of experimental colitis $(59,60)$. Of note, treatment with ADA inhibitor alleviated the severity of inflammation in animals with colitis (60-63). These findings suggest that ADA could represent a potential diagnostic marker as well as therapeutic targets in the treatment of IBDs. Indeed, the simplicity to evaluate the ADA expression and activity associated with a good cost effectiveness ratio represent elements in favor of using this enzyme as a useful inflammatory biomarker in IBD patients, despite this additional controlled studies are needed to further corroborate the role of $\mathrm{ADA}$ as an independent index of inflammation in IBDs.

As previously described, the nucleoside transporters actively participate in maintaining the adenosine levels in the extracellular space. In this regard, Wojtal et al. observed that colonic tissues obtained from patients with IBDs displayed increased mRNA levels of ENT1, ENT2, and CNT2 mRNA, thus leading to hypothesize a reduced bioavailability of endogenous adenosine (64). Interestingly, Aherne et al. reported that the administration of dipyridamole, a ENT 1 and ENT2 blocker, exerted protective effects in a murine DSS model of colitis (65). In this context, the ENT1 gene deletion did not counteract the progression of colitis, while ENT2 gene deletion was protective against intestinal inflammation, suggesting a critical involvement of ENT2 in the onset and development of bowel inflammation (65). The mechanisms underlying the anti-inflammatory effects of ENT2 inhibition or deficiency resulted from the increased levels of extracellular adenosine that exerted its protective effects through $\mathrm{A}_{2 \mathrm{~B}}$ receptor activation (65). Unfortunately, no data are available about the beneficial effects of a pharmacological modulation of ENT2 in other murine models of colitis, not allowing a comprehensive evaluation of its efficacy in intestinal inflammation supported by other immune paradigms.

Overall, current human and pre-clinical evidence support the contention that pharmacological modulation of purinergic pathways is a suitable therapeutic approach for the treatment of bowel inflammation. In particular, $A_{2 A}$ and $A_{3}$ receptor agonists displayed beneficial effects in intestinal dysfunctions associated with inflammatory bowel disorders, including visceral pain, diarrhea, ischemia and functional disorders. However, the role of purinergic system in the modulation of digestive functions still remains poorly understood and deserves extensive future investigations.

\section{Role of Adenosine System in Abdominal Pain}

Abdominal pain is a symptom frequently associated with the presence of IBDs (66). Indeed, a number of patients in the acute phase of IBD will experience pain, typically improving upon disease activity decrease (66). Of note, a large part of IBD patients continue experiencing pain also under clinical remission (66).

Over the past years, huge efforts have been addressed to characterize the role of the endogenous mediators released during enteric dysfunctions and involved in pain perception (1). In this regard, adenosine receptors are actively involved in the rearrangement of enteric sensory pathways (1).

At present, the role of adenosine in the pathophysiology of visceral pain has been scarcely deepened and often the available evidences are conflicting $(67,68)$. Pre-clinical studies pointed out an inhibitory effect exerted by adenosine, via $A_{1}$ receptor activation, on pain transmission both at pre-synaptic level, counteracting the pain-associated neurotransmitter release, such as glutamate, calcitonin gene-related peptide and substance $\mathrm{P}$, and at post-synaptic level, through membrane cell hyperpolarization $(68,69)$. Sohn et al. reported that the intrathecal administration of the $A_{1}$ receptor agonist R-PIA, but not the $\mathrm{A}_{2 \mathrm{~A}}$ receptor agonist CGS-21680 hydrochloride, decreased the visceromotor responses (70). Currently, some authors paid greater attention to the potential anti-nociceptive effects of $\mathrm{A}_{3}$ agonists $(71,72)$. For instance, Hou et al. demonstrated the analgesic effects of $\mathrm{A}_{3}$ receptor agonists in a mouse model of visceral pain following experimental colitis (71). At present, no data are available about the putative analgesic effect of $\mathrm{A}_{2 \mathrm{~A}}$ ligands on abdominal pain associated with experimental colitis. This is an intriguing point to address, since as previously described, the $\mathrm{A}_{2 \mathrm{~A}}$ agonists are actively under evaluation for IBD management based on their marked immunomodulatory effects.

\section{Role of Adenosine System in Enteric Dysmotility Associated With IBD}

Over the years, increasing efforts have been addressed to unravel the link between the enteric inflammation and the neuronal alterations in the digestive tract. Inflammation-induced 
changes occur in several neuronal compartments, including the sympathetic prevertebral ganglia, the dorsal root ganglia, and the enteric ganglia (73).

In this context, the evaluation about the involvement of adenosine pathways in the pathophysiology of enteric dysmotility associated with IBDs, has become an area of active investigation $(1,74,75)$. Several evidences highlighted a marked reorganization of adenosine receptor expression and activity in the presence of intestinal inflammation $(1,17,74,75)$. Different murine model of chronic bowel inflammation revealed a reduced modulatory role by $A_{1}$ receptors in the small and large bowel $(76,77)$. The loss of $A_{1}$ receptor activity has been ascribed to a sustained exposure at marked concentrations of adenosine, leading to a receptor desensitization (14). A reduced inhibitory modulation via $A_{1}$ receptors on colonic cholinergic responses have been observed in a rat model of DNBS-colitis. However, the authors related this event to an increased degradation of endogenous adenosine, with a consequent reduction of its bioavailability, rather than to a receptor desensitization (14). Accordingly, Antonioli et al. reported a limited $A_{1}$ receptor activation arising from a sitespecific production of adenosine, operated by the enzyme CD73, preferentially in the $A_{2 A}$ receptor biophase (14), previously reported as critically involved in the modulation of colonic nitrergic transmission in DNBS-treated rats (78). In the presence of intestinal inflammation, a reorganization of the receptor expression and function as well as the presence of functional interplays with metabolic pathways, have been described also for $A_{2 B}$ receptors (59). Indeed, the inhibitory control exerted by $A_{2 B}$ receptors on colonic contractile responses was impaired in the presence of experimental colitis, despite an up regulation of such receptors in the colonic neuromuscular layer from inflamed animals (59). Molecular investigations demonstrated the co-localization of adenosine deaminase with the $\mathrm{A}_{2 \mathrm{~B}}$ receptor, suggesting a functional interplay, where adenosine deaminase, catabolizing the endogenous adenosine, reduced $\mathrm{A}_{2 \mathrm{~B}}$ receptor activation (59). In accordance, adenosine deaminase has also been shown to play a modulatory role in the activity of the $A_{3}$ receptor in the inflamed colon (79).

Analogously to what was reported for $\mathrm{A}_{2 \mathrm{~B}}$ receptors, the presence of colonic inflammation was characterized by the loss of the $\mathrm{A}_{3}$ receptor inhibitory activity, an upregulation of functioning $A_{3}$ receptors occurred (79). This altered $\mathrm{A}_{3}$ receptor expression occurred concomitantly with an increase in adenosine deaminase expression in the colonic neuromuscular compartment of rats with colitis, thus decreasing the bioavailability of endogenous adenosine in the $\mathrm{A}_{3}$ receptor microenvironment (79). Based on these evidences, the pharmacological blockade of adenosine deaminase may represent an intriguing strategy to limit the inflammatory process and contextually counteract the enteric motor alterations typically observed in IBD patients.

\section{REFERENCES}

1. Antonioli L, Fornai M, Colucci R, Ghisu N, Tuccori M, Del Tacca M, et al. Regulation of enteric functions by adenosine:

\section{CONCLUDING REMARKS}

The etiopathogenesis of IBD is still poorly understood, despite a number of recent evidences revealing that enhanced knowledge about the immunological mechanisms underlying IBD onset and progression represent an interesting target to design and synthesize innovative therapeutic strategies (80). The current available pharmacological options are effective, but unfortunately some of these drugs displayed marked adverse events, such as infections or an enhanced risk of neoplastic diseases or they lose their effectiveness over time. Indeed, about one third of the patients show a slight response to these therapies (80).

A number of pre-clinical studies revealed the involvement of the adenosine system in the modulation of immune, functional and sensory systems of the gastrointestinal tract (81). In this regard, an increasing interest has been focused toward the $\mathrm{A}_{2 \mathrm{~A}}$ and $\mathrm{A}_{3}$ receptor agonists as interesting targets to generate novel pharmacological entities useful to manage the digestive dysfunctions. Indeed, the use of selective $\mathrm{A}_{2 \mathrm{~A}}$ or $\mathrm{A}_{3}$ receptor agonists showed beneficial effects in counteracting the inflammatory burst in murine models of colitis, acting on both the innate and acquired component of the immune system (82-85). In parallel, the stimulation of such receptor subtype revealed to exert a significant role in the regulation of colonic neuromuscular activity in the presence of bowel inflammation $(77,79)$. In particular, the engagement of $\mathrm{A}_{2 \mathrm{~A}}$ or $\mathrm{A}_{3}$ receptors by selective agonists appear to be an interesting method of management for IBD patients displaying an increased gut motility and diarrhea $(77,79)$. A number of encouraging data are emerging about the modulatory role of adenosine receptors on visceral sensitivity $(71,72)$. The $A_{3}$ receptor agonists highlighted a pain-relieving mediated through $\mathrm{N}$-type $\mathrm{Ca}^{2+}$ channel block and action potential inhibition, suggesting the $A_{3}$ receptor agonists as an innovative approach to manage the visceral pain (59).

These data spurred the interest of the scientific community toward the development of novel ligands acting selectively on adenosinergic receptors/enzymes. These novel pharmacological tools will allow to better deepen the pathophysiological meaning as well as the putative therapeutic relevance of the adenosine pathway, paving the way to the development of novel therapeutic options useful for the treatment of IBDs.

\section{AUTHOR CONTRIBUTIONS}

LA, MF, CP, LB, ZN, and CB participate to bibliographic research, to write and revised the manuscript. All authors contributed to the article and approved the submitted version.

pathophysiological and pharmacological implications. Pharmacol Ther (2008) 120:233-53. doi: 10.1016/j.pharmthera.2008.08.010

2. Antonioli L, Fornai M, Colucci R, Tuccori M, Blandizzi C. A holistic view of adenosine in the control of intestinal neuromuscular 
functions: the enteric 'purinome' concept. Br J Pharmacol. (2011) 164:1577-9. doi: 10.1111/j.1476-5381.2011.01529.x

3. Peleli M, Fredholm BB, Sobrevia L, Carlstrom M. Pharmacological targeting of adenosine receptor signaling. Mol Aspects Med. (2017) 55:48. doi: 10.1016/j.mam.2016.12.002

4. Antonioli L, Pacher P, Vizi ES, Hasko G. CD39 and CD73 in immunity and inflammation. Trends Mol Med. (2013) 19:35567. doi: 10.1016/j.molmed.2013.03.005

5. Antonioli L, Colucci R, La Motta C, Tuccori M, Awwad O, Da Settimo F, et al. Adenosine deaminase in the modulation of immune system and its potential as a novel target for treatment of inflammatory disorders. Curr Drug Targets. (2012) 13:842-62. doi: 10.2174/138945012800564095

6. Antonioli L, Blandizzi C, Pacher P, Hasko G. The purinergic system as a pharmacological target for the treatment of immune-mediated inflammatory diseases. Pharmacol Rev. (2019) 71:345-82. doi: 10.1124/pr.117.014878

7. Antonioli L, Blandizzi C, Pacher P, Hasko G. Immunity, inflammation and cancer: a leading role for adenosine. Nat Rev Cancer. (2013) 13:84257. doi: $10.1038 / \mathrm{nrc} 3613$

8. Tindemans I, Joosse ME, Samsom JN. Dissecting the heterogeneity in T-cell mediated inflammation in IBD. Cells. (2020) 9:110. doi: 10.3390/cells9010110

9. Neurath MF. Cytokines in inflammatory bowel disease. Nat Rev Immunol. (2014) 14:329-42. doi: 10.1038/nri3661

10. Neurath MF. Targeting immune cell circuits and trafficking in inflammatory bowel disease. Nat Immunol. (2019) 20:9709. doi: 10.1038/s41590-019-0415-0

11. Coskun M. Intestinal epithelium in inflammatory bowel disease. Front Med. (2014) 1:24. doi: 10.3389/fmed.2014.00024

12. Wang YF, Zhang H, Ouyang Q. Clinical manifestations of inflammatory bowel disease: east and west differences. J Dig Dis. (2007) 8:1217. doi: 10.1111/j.1443-9573.2007.00296.x

13. Brand S. Crohn's disease: Thl, Th17 or both? The change of a paradigm: new immunological and genetic insights implicate Th17 cells in the pathogenesis of Crohn's disease. Gut. (2009) 58:1152-67. doi: 10.1136/gut.2008.163667

14. Goyal N, Rana A, Ahlawat A, Bijjem KR, Kumar P. Animal models of inflammatory bowel disease: a review. Inflammopharmacology. (2014) 22:21933. doi: 10.1007/s10787-014-0207-y

15. Randhawa PK, Singh K, Singh N, Jaggi AS. A review on chemical-induced inflammatory bowel disease models in rodents. Kor J Physiol Pharmacol. (2014) 18:279-88. doi: 10.4196/kjpp.2014.18.4.279

16. Hartman KG, Bortner JD Jr, Falk GW, Ginsberg GG, Jhala N, Yu MG, et al. Modeling human gastrointestinal inflammatory diseases using microphysiological culture systems. Exp Biol Med. (2014) 239:110823. doi: $10.1177 / 1535370214529388$

17. Dal Ben D, Antonioli L, Lambertucci C, Fornai M, Blandizzi C, Volpini R. Purinergic ligands as potential therapeutic tools for the treatment of inflammation-related intestinal diseases. Front Pharmacol. (2018) 9:212. doi: 10.3389/fphar.2018.00212

18. Rybaczyk L, Rozmiarek A, Circle K, Grants I, Needleman B, Wunderlich JE, et al. New bioinformatics approach to analyze gene expressions and signaling pathways reveals unique purine gene dysregulation profiles that distinguish between CD and UC. Inflamm Bowel Dis. (2009) 15:97184. doi: $10.1002 /$ ibd.20893

19. Tian T, Zhou Y, Feng X, Ye S, Wang H, Wu W, et al. MicroRNA-16 is putatively involved in the NF-kappaB pathway regulation in ulcerative colitis through adenosine A2a receptor (A2aAR) mRNA targeting. Sci Rep. (2016) 6:30824. doi: 10.1038/srep30824

20. Zhang H, Li W. microRNA-15 activates NF-kappaB pathway via down regulating expression of adenosine A2 receptor in ulcerative colitis. Cell Physiol Biochem. (2018) 51:1932-44. doi: 10.1159/000495718

21. Naganuma M, Wiznerowicz EB, Lappas CM, Linden J, Worthington MT, Ernst PB. Cutting edge: critical role for A2A adenosine receptors in the T cell-mediated regulation of colitis. J Immunol. (2006) 177:27659. doi: 10.4049/jimmunol.177.5.2765

22. Rahimian R, Fakhfouri G, Daneshmand A, Mohammadi H, Bahremand A, Rasouli MR, et al. Adenosine A2A receptors and uric acid mediate protective effects of inosine against TNBS-induced colitis in rats. Eur J Pharmacol. (2010) 649:376-81. doi: 10.1016/j.ejphar.2010.09.044
23. Antonioli L, El-Tayeb A, Pellegrini C, Fornai M, Awwad O, Giustarini G, et al. Anti-inflammatory effect of a novel locally acting A2A receptor agonist in a rat model of oxazolone-induced colitis. Purinergic Signal. (2018) 14:2736. doi: 10.1007/s11302-017-9591-2

24. Selmeczy Z, Csoka B, Pacher P, Vizi ES, Hasko G. The adenosine A2A receptor agonist CGS 21680 fails to ameliorate the course of dextran sulphate-induced colitis in mice. Inflamm Res. (2007) 56:204-9. doi: 10.1007/s00011-006-6150-7

25. Hoffmann JC, Peters K, Henschke S, Herrmann B, Pfister K, Westermann $\mathrm{J}$, et al. Role of $\mathrm{T}$ lymphocytes in rat 2,4,6-trinitrobenzene sulphonic acid (TNBS) induced colitis: increased mortality after gammadelta $\mathrm{T}$ cell depletion and no effect of alphabeta T cell depletion. Gut. (2001) 48:48995. doi: 10.1136/gut.48.4.489

26. Boirivant M, Fuss IJ, Chu A, Strober W. Oxazolone colitis: a murine model of T helper cell type 2 colitis treatable with antibodies to interleukin 4. J Exp Med. (1998) 188:1929-39. doi: 10.1084/jem.188.10.1929

27. Dieleman LA, Ridwan BU, Tennyson GS, Beagley KW, Bucy RP, Elson CO. Dextran sulfate sodium-induced colitis occurs in severe combined immunodeficient mice. Gastroenterology. (1994) 107:1643-52. doi: 10.1016/0016-5085(94)90803-6

28. Odashima M, Bamias G, Rivera-Nieves J, Linden J, Nast CC, Moskaluk CA, et al. Activation of $\mathrm{A} 2 \mathrm{~A}$ adenosine receptor attenuates intestinal inflammation in animal models of inflammatory bowel disease. Gastroenterology. (2005) 129:26-33. doi: 10.1053/j.gastro.2005.05.032

29. Okayasu I, Hatakeyama S, Yamada M, Ohkusa T, Inagaki Y, Nakaya R. A novel method in the induction of reliable experimental acute and chronic ulcerative colitis in mice. Gastroenterology. (1990) 98:694702. doi: 10.1016/0016-5085(90)90290-H

30. Ohkusa T, Okayasu I, Tokoi S, Araki A, Ozaki Y. Changes in bacterial phagocytosis of macrophages in experimental ulcerative colitis. Digestion. (1995) 56:159-64. doi: 10.1159/000201236

31. Colgan SP, Fennimore B, Ehrentraut SF. Adenosine and gastrointestinal inflammation. J Mol Med. (2013) 91:157-64. doi: 10.1007/s00109-012-0990-0

32. Hasko G, Csoka B, Nemeth ZH, Vizi ES, Pacher P. A(2B) adenosine receptors in immunity and inflammation. Trends Immunol. (2009) 30:26370. doi: 10.1016/j.it.2009.04.001

33. Kolachala V, Asamoah V, Wang L, Obertone TS, Ziegler TR, Merlin D, et al. TNF-alpha upregulates adenosine $2 \mathrm{~b}(\mathrm{~A} 2 \mathrm{~b})$ receptor expression and signaling in intestinal epithelial cells: a basis for A2bR overexpression in colitis. Cell Mol Life Sci. (2005) 62:2647-57. doi: 10.1007/s00018-005-5328-4

34. Yang D, Zhang Y, Nguyen HG, Koupenova M, Chauhan AK, Makitalo M, et al. The A2B adenosine receptor protects against inflammation and excessive vascular adhesion. J Clin Investig. (2006) 116:1913-23. doi: 10.1172/JCI27933

35. Kolachala V, Ruble B, Vijay-Kumar M, Wang L, Mwangi S, Figler H, et al. Blockade of adenosine A2B receptors ameliorates murine colitis. $\mathrm{Br} \mathrm{J}$ Pharmacol. (2008) 155:127-37. doi: 10.1038/bjp.2008.227

36. Kolachala VL, Vijay-Kumar M, Dalmasso G, Yang D, Linden J, Wang $\mathrm{L}$, et al. A2B adenosine receptor gene deletion attenuates murine colitis. Gastroenterology. (2008) 135:861-70. doi: 10.1053/j.gastro.2008.05.049

37. Frick JS, MacManus CF, Scully M, Glover LE, Eltzschig HK, Colgan SP. Contribution of adenosine A2B receptors to inflammatory parameters of experimental colitis. J Immunol. (2009) 182:495764. doi: 10.4049/jimmunol.0801324

38. Aherne CM, Saeedi B, Collins CB, Masterson JC, McNamee EN, Perrenoud $\mathrm{L}$, et al. Epithelial-specific A2B adenosine receptor signaling protects the colonic epithelial barrier during acute colitis. Mucosal Immunol. (2015) 8:1324-38. doi: $10.1038 / \mathrm{mi} .2015 .22$

39. Wu W, He Y, Feng X, Ye S, Wang H, Tan W, et al. MicroRNA-206 is involved in the pathogenesis of ulcerative colitis via regulation of adenosine A3 receptor. Oncotarget. (2017) 8:705-21. doi: 10.18632/oncotarget.13525

40. Ren T, Grants I, Alhaj M, McKiernan M, Jacobson M, Hassanain HH, et al. Impact of disrupting adenosine $\mathrm{A}(3)$ receptors $(\mathrm{A}(3)(-) /(-) \mathrm{AR})$ on colonic motility or progression of colitis in the mouse. Inflamm Bowel Dis. (2011) 17:1698-713. doi: 10.1002/ibd.21553

41. Ochaion A, Bar-Yehuda S, Cohen S, Barer F, Patoka R, Amital H, et al. The anti-inflammatory target $\mathrm{A}(3)$ adenosine receptor is over-expressed in rheumatoid arthritis, psoriasis and Crohn's disease. Cell Immunol. (2009) 258:115-22. doi: 10.1016/j.cellimm.2009.03.020 
42. Ren TH, Lv MM, An XM, Leung WK, Seto WK. Activation of adenosine A3 receptor inhibits inflammatory cytokine production in colonic mucosa of patients with ulcerative colitis by down-regulating the nuclear factor-kappa B signaling. J Dig Dis. (2020) 21:38-45. doi: 10.1111/1751-2980.12831

43. Mabley J, Soriano F, Pacher P, Hasko G, Marton A, Wallace R, et al. The adenosine A3 receptor agonist, N6-(3-iodobenzyl)-adenosine-5'-Nmethyluronamide, is protective in two murine models of colitis. Eur $J$ Pharmacol. (2003) 466:323-9. doi: 10.1016/S0014-2999(03)01570-X

44. Guzman J, Yu JG, Suntres Z, Bozarov A, Cooke H, Javed N, et al. ADOA3R as a therapeutic target in experimental colitis: proof by validated high-density oligonucleotide microarray analysis. Inflamm Bowel Dis. (2006) 12:76689. doi: 10.1097/00054725-200608000-00014

45. Guarner F, Malagelada JR. Role of bacteria in experimental colitis. Best practice \& research. Clin Gastroenterol. (2003) 17:793-804. doi: 10.1016/S1521-6918(03)00068-4

46. Gibson DJ, Elliott L, McDermott E, Tosetto M, Keegan D, Byrne K, et al. Heightened expression of CD39 by regulatory T lymphocytes is associated with therapeutic remission in inflammatory bowel disease. Inflamm Bowel Dis. (2015) 21:2806-14. doi: 10.1097/MIB.0000000000000566

47. Bai A, Moss A, Kokkotou E, Usheva A, Sun X, Cheifetz A, et al. CD39 and CD161 modulate Th17 responses in Crohn's disease. J Immunol. (2014) 193:3366-77. doi: 10.4049/jimmunol.1400346

48. Bai A, Moss A, Rothweiler S, Longhi MS, Wu Y, Junger WG, et al. $\mathrm{NADH}$ oxidase-dependent CD39 expression by CD8(+) $\mathrm{T}$ cells modulates interferon gamma responses via generation of adenosine. Nat Commun. (2015) 6:8819. doi: 10.1038/ncomms9819

49. Friedman DJ, Kunzli BM, YI AR, Sevigny J, Berberat PO, Enjyoji K, et al. From the Cover: CD39 deletion exacerbates experimental murine colitis and human polymorphisms increase susceptibility to inflammatory bowel disease. Proc Natl Acad Sci USA. (2009) 106:16788-93. doi: 10.1073/pnas.0902869106

50. Kunzli BM, Berberat PO, Dwyer K, Deaglio S, Csizmadia E, Cowan P, et al. Variable impact of CD39 in experimental murine colitis. Dig Dis Sci. (2011) 56:1393-403. doi: 10.1007/s10620-010-1425-9

51. Louis NA, Robinson AM, MacManus CF, Karhausen J, Scully M, Colgan SP. Control of IFN-alphaA by CD73: implications for mucosal inflammation. $J$ Immunol. (2008) 180:4246-55. doi: 10.4049/jimmunol.180.6.4246

52. Sotnikov I, Louis NA. CD73-dependent regulation of interferon alphaA and interleukin-10 in the inflamed mucosa. Sci World J. (2010) 10:216780. doi: 10.1100/tsw.2010.203

53. Colgan SP, Eltzschig HK, Eckle T, Thompson LF. Physiological roles for ecto-5'-nucleotidase (CD73). Purinergic Signal. (2006) 2:351-60. doi: 10.1007/s11302-005-5302-5

54. Synnestvedt K, Furuta GT, Comerford KM, Louis N, Karhausen J, Eltzschig $\mathrm{HK}$, et al. Ecto-5'-nucleotidase (CD73) regulation by hypoxia-inducible factor-1 mediates permeability changes in intestinal epithelia. J Clin Investig. (2002) 110:993-1002. doi: 10.1172/JCI0215337

55. Doherty GA, Bai A, Hanidziar D, Longhi MS, Lawlor GO, Putheti P, et al. CD73 is a phenotypic marker of effector memory Th17 cells in inflammatory bowel disease. Eur J Immunol. (2012) 42:3062-72. doi: 10.1002/eji.201 242623

56. Bynoe MS, Waickman AT, Mahamed DA, Mueller C, Mills JH, Czopik A. CD73 is critical for the resolution of murine colonic inflammation. J Biomed Biotechnol. (2012) 2012:260983. doi: 10.1155/2012/260983

57. Maor I, Rainis T, Lanir A, Lavy A. Adenosine deaminase activity in patients with Crohn's disease: distinction between active and nonactive disease. Eur J Gastroenterol Hepatol. (2011) 23:598-602. doi: 10.1097/MEG.0b013e328346e205

58. Beyazit Y, Koklu S, Tas A, Purnak T, Sayilir A, Kurt M, et al. Serum adenosine deaminase activity as a predictor of disease severity in ulcerative colitis. $J$ Crohn's Colitis. (2012) 6:102-7. doi: 10.1016/j.crohns.2011.07.010

59. Antonioli L, Fornai M, Awwad O, Giustarini G, Pellegrini C, Tuccori M, et al. Role of the $\mathrm{A}(2 \mathrm{~B})$ receptor-adenosine deaminase complex in colonic dysmotility associated with bowel inflammation in rats. Br J Pharmacol. (2014) 171:1314-29. doi: 10.1111/bph.12539

60. Antonioli L, Fornai M, Colucci R, Awwad O, Ghisu N, Tuccori M, et al. The blockade of adenosine deaminase ameliorates chronic experimental colitis through the recruitment of adenosine A2A and A3 receptors. J Pharmacol Exp Ther. (2010) 335:434-42. doi: 10.1124/jpet.110.171223
61. Antonioli L, Fornai M, Colucci R, Ghisu N, Da Settimo F, Natale G, et al. Inhibition of adenosine deaminase attenuates inflammation in experimental colitis. J Pharmacol Exp Ther. (2007) 322:435-42. doi: 10.1124/jpet.107.122762

62. La Motta C, Sartini S, Mugnaini L, Salerno S, Simorini F, Taliani S, et al. Exploiting the pyrazolo[3,4-d]pyrimidin-4-one ring system as a useful template to obtain potent adenosine deaminase inhibitors. J Med Chem. (2009) 52:1681-92. doi: 10.1021/jm801427r

63. Brown JB, Lee G, Grimm GR, Barrett TA. Therapeutic benefit of pentostatin in severe IL-10-/- colitis. Inflamm Bowel Dis. (2008) 14:8807. doi: 10.1002/ibd.20410

64. Wojtal KA, Eloranta JJ, Hruz P, Gutmann H, Drewe J, Staumann A, et al. Changes in mRNA expression levels of solute carrier transporters in inflammatory bowel disease patients. Drug Metab Dispos. (2009) 37:18717. doi: $10.1124 / \mathrm{dmd} .109 .027367$

65. Aherne CM, Collins CB, Rapp CR, Olli KE, Perrenoud L, Jedlicka $\mathrm{P}$, et al. Coordination of ENT2-dependent adenosine transport and signaling dampens mucosal inflammation. JCI Insight. (2018) 3:e121521. doi: 10.1172/jci.insight.121521

66. Bielefeldt K, Davis B, Binion DG. Pain and inflammatory bowel disease. Inflamm Bowel Dis. (2009) 15:778-88. doi: 10.1002/ibd.20848

67. Bastia E, Varani K, Monopoli A, Bertorelli R. Effects of A(1) and A(2A) adenosine receptor ligands in mouse acute models of pain. Neurosci Lett. (2002) 328:241-4. doi: 10.1016/S0304-3940(02)00524-4

68. Sawynok J, Liu XJ. Adenosine in the spinal cord and periphery: release and regulation of pain. Prog Neurobiol. (2003) 69:31340. doi: 10.1016/S0301-0082(03)00050-9

69. Patel MK, Pinnock RD, Lee K. Adenosine exerts multiple effects in dorsal horn neurones of the adult rat spinal cord. Brain Res. (2001) 920:1926. doi: 10.1016/S0006-8993(01)02844-X

70. Sohn CI, Park HJ, Gebhart GF. Adenosine receptor agonists modulate visceral hyperalgesia in the rat. Gut Liver. (2008) 2:39-46. doi: 10.5009/gnl.2008.2.1.39

71. Hou T, Xiang H, Yu L, Su W, Shu Y, Li H, et al. Electroacupuncture inhibits visceral pain via adenosine receptors in mice with inflammatory bowel disease. Purinergic Signal. (2019) 15:193-204. doi: 10.1007/s11302-019-09655-4

72. Coppi E, Cherchi F, Fusco I, Failli P, Vona A, Dettori I, et al. Adenosine A3 receptor activation inhibits pronociceptive $\mathrm{N}$-type $\mathrm{Ca} 2+$ currents and cell excitability in dorsal root ganglion neurons. Pain. (2019) 160:110318. doi: 10.1097/j.pain.0000000000001488

73. Mawe GM. Colitis-induced neuroplasticity disrupts motility in the inflamed and post-inflamed colon. J Clin Investig. (2015) 125:949-55. doi: 10.1172/JCI76306

74. Linan-Rico A, Wunderlich JE, Enneking JT, Tso DR, Grants I, Williams $\mathrm{KC}$, et al. Neuropharmacology of purinergic receptors in human submucous plexus: involvement of $\mathrm{P} 2 \mathrm{X}(1), \mathrm{P} 2 \mathrm{X}(2), \mathrm{P} 2 \mathrm{X}(3)$ channels, $\mathrm{P} 2 \mathrm{Y}$ and $\mathrm{A}(3)$ metabotropic receptors in neurotransmission. Neuropharmacology. (2015) 95:83-99. doi: 10.1016/j.neuropharm.2015.02.014

75. Christofi FL. Purinergic receptors and gastrointestinal secretomotor function. Purinergic Signal. (2008) 4:213-36. doi: 10.1007/s11302-008-9104-4

76. De Man JG, Seerden TC, De Winter BY, Van Marck EA, Herman AG, Pelckmans PA. Alteration of the purinergic modulation of enteric neurotransmission in the mouse ileum during chronic intestinal inflammation. Br J Pharmacol. (2003) 139:172-84. doi: 10.1038/sj.bjp. 0705218

77. Antonioli L, Fornai M, Colucci R, Awwad O, Ghisu N, Tuccori M, et al. Differential recruitment of high affinity A1 and A2A adenosine receptors in the control of colonic neuromuscular function in experimental colitis. Eur J Pharmacol. (2011) 650:639-49. doi: 10.1016/j.ejphar.2010.10.041

78. Antonioli L, Fornai M, Colucci R, Ghisu N, Blandizzi C, Del Tacca M. A2a receptors mediate inhibitory effects of adenosine on colonic motility in the presence of experimental colitis. Inflamm Bowel Dis. (2006) 12:11722. doi: 10.1097/01.MIB.0000198535.13822.a9

79. Antonioli L, Fornai M, Colucci R, Ghisu N, Tuccori M, Awwad O, et al. Control of enteric neuromuscular functions by purinergic $\mathrm{A}(3)$ receptors in normal rat distal colon and experimental bowel inflammation. Br J Pharmacol. (2010) 161:856-71. doi: 10.1111/j.1476-5381.2010.00917.x

80. Catalan-Serra I, Brenna O. Immunotherapy in inflammatory bowel disease: novel and emerging treatments. Human Vacc Immunother. (2018) 14:2597611. doi: 10.1080/21645515.2018.1461297 
81. Antonioli L, Fornai M, Colucci R, Ghisu N, Tuccori M, Del Tacca M, et al. Pharmacological modulation of adenosine system: novel options for treatment of inflammatory bowel diseases. Inflamm Bowel Dis. (2008) 14:56674. doi: 10.1002/ibd.20316

82. Csoka B, Himer L, Selmeczy Z, Vizi ES, Pacher P, Ledent C, et al. Adenosine A2A receptor activation inhibits $\mathrm{T}$ helper 1 and $\mathrm{T}$ helper 2 cell development and effector function. FASEB J. (2008) 22:3491-9. doi: 10.1096/fj.08-107458

83. Ramanathan M, Luo W, Csoka B, Hasko G, Lukashev D, Sitkovsky MV, et al. Differential regulation of HIF-1alpha isoforms in murine macrophages by TLR4 and adenosine A(2A) receptor agonists. J Leukoc Biol. (2009) 86:6819. doi: 10.1189/jlb.0109021

84. Himer L, Csoka B, Selmeczy Z, Koscso B, Pocza T, Pacher P, et al. Adenosine A2A receptor activation protects $\mathrm{CD} 4+\mathrm{T}$ lymphocytes against activationinduced cell death. FASEB J. (2010) 24:2631-40. doi: 10.1096/fj.10-155192

85. Csoka B, Selmeczy Z, Koscso B, Nemeth ZH, Pacher P, Murray PJ, et al. Adenosine promotes alternative macrophage activation via A2A and A2B receptors. FASEB J. (2012) 26:376-86. doi: 10.1096/fj.11190934

Conflict of Interest: The authors declare that the research was conducted in the absence of any commercial or financial relationships that could be construed as a potential conflict of interest.

The handling editor declared a past co-authorship with one of the authors LA.

Copyright (c) 2020 Antonioli, Fornai, Pellegrini, Bertani, Nemeth and Blandizzi. This is an open-access article distributed under the terms of the Creative Commons Attribution License (CC BY). The use, distribution or reproduction in other forums is permitted, provided the original author(s) and the copyright owner(s) are credited and that the original publication in this journal is cited, in accordance with accepted academic practice. No use, distribution or reproduction is permitted which does not comply with these terms. 